\title{
ANALISIS PENGARUH HARGA PRODUK DAN KUALITAS PRODUK TERHADAP KEPUASAN PELANGGAN (Studi Kasus Jasa bengkel Alin Motor Semarang)
}

\author{
Oleh: \\ Ezra Hendri Noto \\ Alumni STIE Totalwin Semarang \\ Lukmanul Hakim \\ Dosen Tetap STIE Totalwin Semarang
}

\begin{abstract}
This research is motivated complaints or customer dissatisfaction on product price and quality products provided Alin Motorcycle Workshop. These complaints should be dealt with either by the Workshop Alin Motor, because if not addressed properly, then the customer will tell the disappointing experiences to others, so it will worsen the image and the existence of the workshop. Complaints can be minimized by taking the necessary steps, so that customers will be satisfied with the price and quality and support provided by the workshop. Customer satisfaction in the long run can create customer loyalty towards Alin Motor Repair. The purpose of this study was to analyze the effect of product price and quality products which include physical evidence, reliability, product durability, to customer satisfaction Alin Motor Repair. This research was conducted by questionnaire to 100 customers Alin Motor Repair obtained by using purposive sampling technique was then performed an analysis of the data obtained in the form of quantitative analysis Quantitative analysis includes the validity and reliability test, the classical assumption test, multiple regression analysis, the test Goodness of Fit through $F$ test and t test and the coefficient of determination $\left(R^{2}\right)$. The results showed that the coefficient of determination which looks at the value of Adjusted $R$ Square of 0.224 which means that customer satisfaction can be explained by the independent variable in this study is the price of the product, and the quality of products, by $50 \%$. While the remaining $22.4 \%$ can be explained by other variables outside of the three variables used in this study. Partially based on the results of the test variables in this study are positive and significant effect where the price of products had the greatest influence than other variables in this study, while the quality of the product has a positive effect on customer satisfaction. F test showed that simultaneous or jointly variable in this study is the price produkdan quality products and a significant positive effect on customer satisfaction.
\end{abstract}

Keywords: product price, product quality, customer satisfaction.

\section{PENDAHULUAN}

Saat ini dunia bisnis jasa berkembang dengan sangat pesat Adanya permintaan yang semakin banyak maka perusahaan jasa bengkel motor 
dituntut dapat beroprasi secara lebih baik dan efektif dalam menghadapi era globalisasi, berbagai cara yang diterapakan untuk memperoleh laba atau keuntungan yang maksimum. Memperhatikan harga dan kualitas produk merupakan suatu kepentianga bagi jasa bengkel Alin motor agar dapat terus mempertahankan image dimata pelanggan. Dan dengan mengutamakan harga produk, kualitas produk yang bagus dan bekualiats maka pembeli akan memudahkan perusahaan mencapai tujuan perusahaan yaitu mencapai laba yang maksimal melalui peningkatan jumlah oleh pelanggan secara terus menerus. Peningkatan jumlah pelanggan ini dapat terjadi jika pelanggan puas akan harga produk yang terjangkau oleh pelanggan dan kualitas produk yang berkualitas akan diperhatikan oleh perusahaan karena itu hal tersebut menyangkut kemampuan atau daya beli pelanggan,oleh karena itu perusahaan dalam menentukan harga produk harus menetapkannya dengan hati-hati dengan melihat faktor-faktor yang dapat mempengaruhi harga produk dan kualitas produk tersebut. Berikut ini adalah data penjualan target sparepart oli Yamaha lube, dibengkel Alin motor, Semarang jawa tengah

\section{Data Penjualan Oli mesin Yama lube Bengkel Alin motor Tahun 2014}

\begin{tabular}{|c|c|c|c|}
\hline No & Bulan & $\begin{array}{c}\text { Keterangan Target } \\
\text { Penjualan oli mesin } \\
\text { Yamaha lube }\end{array}$ & $\begin{array}{c}\text { Penjualan Oli mesin } \\
\text { Yamaha lube } \\
2014\end{array}$ \\
\hline 1 & Januari & 25 Oli mesin & 25 Oli mesin \\
2 & Febuari & 25 Oli mesin & 15 Oli Mesin \\
3 & Maret & 25 Oli mesin & 9 Oli mesin \\
4 & April & 25 Oli mesin & 10 Oli mesin \\
5 & Mei & 25 Oli mesin & 7 Oli mesin \\
6 & Juni & 25 Oli mesin & 19 Oli mesin \\
7 & Juli & 25 Oli mesin & 7 Oli mesin \\
8 & Agustus & 25 Oli mesin & 14 Oli mesin \\
9 & September & 25 Oli mesin & 13 Oli mesin \\
10 & Oktober & 25 Oli mesin & 9 Oli mesin \\
11 & Nopember & 25 Oli mesin & 17 Oli mesin \\
12 & Desember & 25 Oli mesin & 8 Oli mesin \\
\hline
\end{tabular}

\section{Rumusan Masalah}

Dari rumusan masalah diatas akan menimbulkan pertanyaan penelitian sebagai berikut: 
1. Apakah harga produk berpengaruh terhadap kepuasan pelanggan pada jasa bengkel motor?

2. Apakahkualitas produk berpengaruh terhadap kepuasan pelanggan pada jasa bengkel motor?

\section{Tujuan penelitian}

1. Untuk menganalisis apakah harga produk berpengaruh terhadap kepuasan pelanggan pada bengkel motor.

2. Untuk menganalisis apakah kualitas produk berpengaruh terhadap kepuasan pelanggan pada bengkel motor.

\section{Manfaat penelitian}

Manfaat penelitian yang dikemukakan adalah sebagai berikut: Sebagai masukan bagi pihak bengkel alin motor Semarang, mengenai factor faktor yang mempengaruhi kepuasan pelanggannya, sehingga dapat dijadikan pertimbangan dalam pengembangan strategi di masa yang akan datang. Penelitian ini juga berguna bagi para perusahaan-perusahaan lain sebagai masukan dalam mengembangkan kepuasan pelanggannya.

\section{LANDASAN TEORI}

\section{Manajemen Pemasaran}

Manajemen pemasaran merupakan proses perencanaan dan pelaksanaan pemikiran, penetapan harga, kualitas produk serta menyalurkan gagasan barang dan jasa untuk mendapatkan pertukaran yang memenuhi sasaran-sasaran individu dalam organisasi (Kotler \& Keller 2007).

Dalam bisnis selalu ada kompetisi antar perusahaan. Perusahaan akan terus berusaha untuk memperluas pasar dan mempertahankan eksistensi perusahaan. Aktivitas perusahaan dalam pemasaran ini untuk menentukan arah perusahaan agar mampu merekrut keuntungan yang banyak.

\section{Kepuasan Pelanggan}

Kepuasan pelanggan yang dikemukakan oleh Hasan (2008)'Kepuasan pelanggan adalah kepuasan yang berlanjut menjadi kepuasan pelanggan yang berujung pada peningkatan volume penjualan yang lebih besar, aset lebih produktif danreturn on invesment yang lebih tinggi”. Lerbin (2005), Memberikandefinisi kepuasan pelanggan adalah sebagai hasil penelitian 
pelanggan terhadap apa yang diharapkannya dengan membeli dan menggunakan suatu produk dan kualitas produk, Harapan itu lantas dibandingkan dengan persepsinya terhadap kinerja yang diterimanya dengan mengkonsumsi produk itu.

\section{Manfaat Kepuasan Pelanggan}

Tjiptono (dalam Setiyawati, 2009) mengungkapkan, kepuasan pelanggandapat memberikan beberapa manfaat, yaitu:

a. Menciptakan hubungan yang harmonis antara perusahaan dan para pelanggan

b. Dapat memberikan dasar yang baik untuk pembelian kembali

c. Mendorong terciptanya loyalitas pelanggan

d. Membentuk rekomendasi dari mulut ke mulut (word of mouth) yang menguntungkan bagi perusahaan.

e. Reputasi Perusahaan di mata pelanggan menjadi baik

f. Dapat meningkatkan laba perusahaan.

\section{Konsep Harga Produk}

Harga adalah sejumlah nilai yang ditukarkan pelanggan yang mengambil manfaat dari memiliki atau menggunakan produk atau jasa yang nilainya ditetapkan oleh pembeli dan penjual melalui tawar-menawar, atau ditetapkan oleh penjual untuk satu harga yang sama terhadap semua pembeli (Umar 1999) Dalam menetapkan harga.

\section{Harga Produk}

Menurut Guntur Efendi (2010) harga merupakan satuan moneter atau ukuran lainnya (termasuk barang atau jasa lainnya) yang ditukarkan agar memperoleh hak kepemilikan atau penggunaan suatu barang atau jasa.Harga merupakan komponen yang berpengaruh langsung terhadap laba perusahaan.Tingkat harga yang ditetapkan mempengaruhi kuantitas yang terjual.Selain itu secara tidak langsung harga juga mempengaruhhi biaya, karena kuantitas yang terjual berpengaruh pada biaya yang ditimbulkan dalam kaitannya dengan efisiensi produksi.Dari sudut pandang konsumen, harga sering kali digunakan sebagai indikator nilai bilamana harga tersebut dihubungkan dengan manfaat yang dirasakan atas suatu barang atau jasa. 


\section{Pengertian Penetapan Harga produk}

Harga adalah salah satu pertimbangan bagi konsumen yang akan mengambil keputusan apakah akan membeli barang tersebut atau tidak dan berapa jumlah yang harus dibeli berdasarkan harga tersebut. Sudah barang tentu keputusan dari konsumen ini tidak hanya didasarkan kepada harga semata-mata, tetapi ada faktor-faktor yang menjadi pertimbangan, misalnya harga produk, dan kualitas produk, dari perusahaan jasa bengkel motor, kepercayaan terhadap kualitas dan sebagainya. Meskipun demikian faktor harga tak boleh diabaikan oleh perusahaan.

\section{Tujuan Penetapan Harga produk}

Tujuan penetapan harga dan sasaran penetapan harga dalam setiap kebijakan harga, tentunya dengan tujuan utama untuk lebih memudahkan manajemen untuk melakukan analisis dan evaluasi terhadap setiap kebijakan yang diambil, sehingga berdasarkan hasil analisis dan evaluasi yang dilakukan, manajemen akan segera membuat/menetapkan kebijakan baru guna memperbaiki kesalahan/kekurangan dari berbagai kebijakan harga yang telah ditetapkan sebelumnya

\section{Kualitas produk}

Produk adalah semua yang bisa ditawarkan dipasar untuk mendapatkan perhatian, permintaan, pemakaian atau konsumsi yang dapat memenuhi keinginan atau kebutuhan konsumen (Sumarni dan J. Supranto, 1997 dalam Tjiptono, 2006).

Kualitas produk mencerminkan kemampuan produk untuk menjalankan tugasnya yang mencakup daya tahan, kehandalan, kemajuan, kekuatan, kemudahan dalam pengemasan, dan reparasi produk dan ciri-ciri lainnya (Kotler dan Armstrong, (1997). 


\section{Kerangka pikir teoritis}

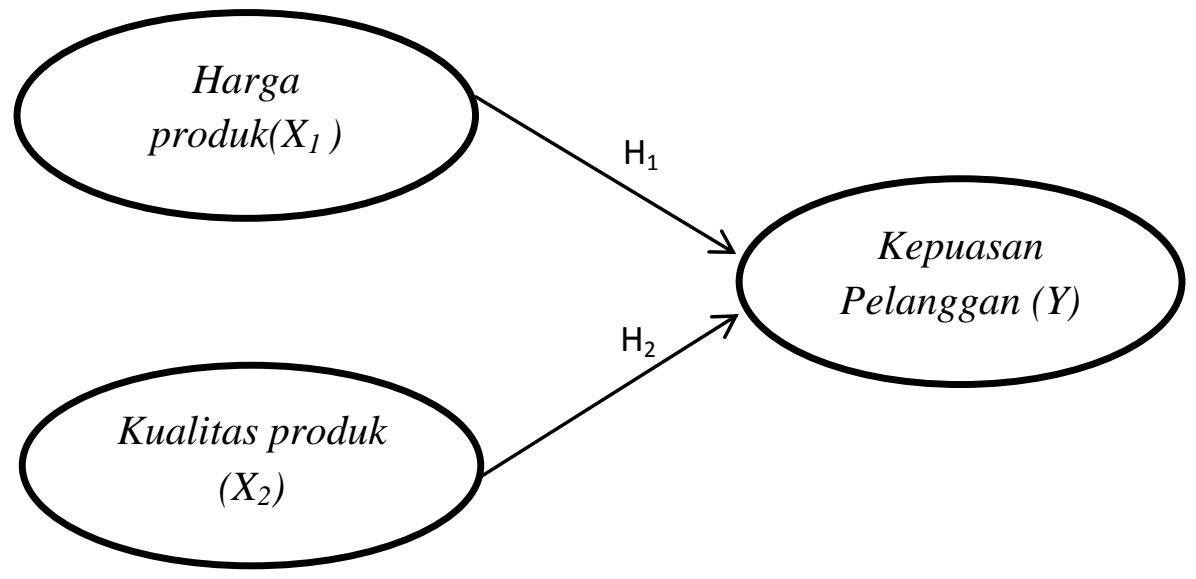

Sumber: Rizki Dharma, 2012

\section{METODE PENELITIAN}

Berikut ini dipaparkan mengenai variabel penelitian dan definisi operasional atas variabel-variabel dan indikator yang digunakan dalam penelitian ini.

\begin{tabular}{|c|c|c|c|}
\hline $\begin{array}{l}\text { Varibel } \\
\text { Penelitian }\end{array}$ & Definisi Operasional & Indikator & Sumber \\
\hline $\begin{array}{l}\text { Harga } \\
\text { produk }\end{array}$ & $\begin{array}{l}\text { Kotler dan Amstrong } \\
\text { (2001) yang menjelaskan } \\
\text { harga sebagai sejumlah } \\
\text { uang yang ditukarkan } \\
\text { untuk sebuah produk atau } \\
\text { jasa. }\end{array}$ & $\begin{array}{l}\text { 1. Terjangka } \\
\text { uan harga } \\
\text { 2. Daya } \\
\text { saing harga. } \\
\text { 3. Kesesuaia } \\
\text { n harga } \\
\text { dengan } \\
\text { manfaat } \\
\text { produk. }\end{array}$ & $\begin{array}{l}\text { Rizki Dharma } \\
\text { (2012) }\end{array}$ \\
\hline $\begin{array}{l}\text { Kualitas } \\
\text { produk }\end{array}$ & $\begin{array}{l}\text { Kualitas produk, kualitas } \\
\text { mencerminkan kemampuan } \\
\text { produk untuk menjalankan } \\
\text { tugasnya yang mencakup } \\
\text { daya } \\
\text { tahan, kehandalan, } \\
\text { kemajuan, } \\
\text { kekuatan, kemudahan } \\
\text { dalam } \\
\text { pengemasan, dan reparasi } \\
\text { produk } \\
\text { dan ciri-ciri lainnya (Kotler } \\
\text { dan }\end{array}$ & $\begin{array}{l}\text { 1. Betuk } \\
\text { produk } \\
\text { 2. Daya } \\
\text { tahan produk } \\
\text { 3. Kehandal } \\
\text { an produk }\end{array}$ & $\begin{array}{l}\text { Resty Avita } \\
\text { Haryanto } \\
(2013)\end{array}$ \\
\hline
\end{tabular}




\begin{tabular}{|l|l|l|l|}
\hline & Armstrong, 1997:279). & & \\
& & & \\
\hline Kepuasan & Kepuasaan pelanggan & 1. Tidakada & Rizki Dharma \\
pelanggan & $\begin{array}{l}\text { Komplain. } \\
\text { adalah hasil yang dirasakan }\end{array}$ & 2. Minat \\
& oleh para pelanggan yang & & \\
& membayar suatu barang & asikan. \\
& atau jasa dan merasakan & & \\
& kinerja sebuah perusahaan. & Tidak \\
& & berpindah \\
ke-produk & yang lain & \\
& & & \\
& &
\end{tabular}

\section{Populasi dan Sampel}

Populasi dalam penelitian ini adalah pemakai produk oli Yamaha lube bengkel Alin motor. Populasi dalam penelitian ini jumlahnya tidak diketahui karena data pelanggan dibengkel Alin motor tidak diberikan oleh pihak dari bengkel Alin motor. Sampel adalah subset dari populasi, terdiri dari beberapa anggota populasi.Subset ini di ambil karena dalam banyak kasus tidak mungkin kita meneliti seluruh anggota populasi, oleh karena itu kita membentuk sebuah perwakilan yang disebut sampel. Dalam penelitian ini jumlah sampelnya 100 orang.

\section{HASIL DAN PEMBAHASAN}

\section{Data Deskriptif}

Data deskriptif menggambarkan beberapa kondisi obyek penelitian secara ringkas yang diperoleh dari hasil pengumpulan dan jawaban kuesioner oleh responden. Responden dalam penelitian ini adalah pelanggan dibengkel Alin motor semarang yang memenuhi syarat. Jumlah populasi yang dijadikan responden penelitian adalah sebesar 100 responden. Namun demikian dari 100 kuesioner yang disebar hanya 51 yang bisa dijadikan data penelitian. Berikut ini rincian dari deskripsi data responden.

\section{Uji Validitas}


Uji validitas digunakan untuk keterkaitan item pertanyaan dalam satu variabel. Pengujian validitas dilakukan dengan menggunakan rumus moment pearson. Pengujian validitas selengkapnya dapat dilihat pada tabel berikut ini.

\begin{tabular}{|c|c|c|c|c|}
\hline No. & Indikator & r hitung & r table & Keterangan \\
\hline 1. & $\begin{array}{l}\text { Harga produk } \\
\text { Indikator } 1 \\
\text { Indikator } 2 \\
\text { Indikator } 3\end{array}$ & $\begin{array}{l}0,812 \\
0,802 \\
0,781\end{array}$ & $\begin{array}{l}0,279 \\
0,279 \\
0,279\end{array}$ & $\begin{array}{l}\text { Valid } \\
\text { Valid } \\
\text { Valid }\end{array}$ \\
\hline 2. & $\begin{array}{l}\text { Kualitas produk } \\
\text { Indikator } 1 \\
\text { Indikator } 2 \\
\text { Indikator } 3\end{array}$ & $\begin{array}{l}0,693 \\
0,732 \\
0,679\end{array}$ & $\begin{array}{l}0,279 \\
0,279 \\
0,279 \\
\end{array}$ & $\begin{array}{l}\text { Valid } \\
\text { Valid } \\
\text { Valid }\end{array}$ \\
\hline 3. & $\begin{array}{l}\text { Kepuasan pelanggan } \\
\text { Indikator } 1 \\
\text { Indikator } 2 \\
\text { Indikator } 3\end{array}$ & $\begin{array}{l}0,634 \\
0,684 \\
0,758\end{array}$ & $\begin{array}{l}0,279 \\
0,279 \\
0,279\end{array}$ & $\begin{array}{l}\text { Valid } \\
\text { Valid } \\
\text { Valid }\end{array}$ \\
\hline
\end{tabular}

Dari tabel diatas dapat diperoleh bahwa semua indikator yang digunakan untuk mengukur variabel Harga Produk, dan kualitas produk terhadap Kepuasan Pelanggan mempunyai $r$ hitung lebih besar dari tabel yaitu $r$ tabel 0,279 sehingga semua indikator tersebut adalah valid.

\section{Uji Reliabilitas}

Uji reliabilitas merupakan pengujian tentang konsistensi hasil jawaban responden, apakah konsisten dari waktu ke waktu. Adapun hasil uji reliabilitas antara Harga Produk dan kualitas produk, terhadap Kepuasan Pelanggan dapat dilihat pada tabel berikut ini.

\section{Uji Reliabilitas}

\begin{tabular}{|l|l|l|l|l|}
\hline No & Indicator & Nilai r alpha & Nilai batas & keterangan \\
\hline 1 & Harga produk & 0,897 & $>0,6$ & Reliabel \\
2 & Kualitas produk & 0,838 & $>0,6$ & Reliabel \\
3 & $\begin{array}{l}\text { Kepuasan } \\
\text { pelanggan }\end{array}$ & 0,830 & $>0,6$ & Reliabel \\
\hline
\end{tabular}

Berdasarkan tabel di atas dapat diketahui bahwa masing-masing variabel antara Harga Produk dan kualitas produk terhadap Kepuasan Pelanggan ternyata 
diperoleh $\mathrm{r}$ Alpha hitung lebih besar cronbach alpha sebesar 0,6. Dengan demikian, maka hasil uji reabilitas terhadap keseluruhan variabel adalah reliabel.

\section{Analisis Regresi Berganda}

Berdasarkan perhitungan regresi berganda antara Harga produk $\left(\mathrm{X}_{1}\right)$, Kualiatas produk $\left(\mathrm{X}_{2}\right)$, terhadap Kepuasan pelanggan(Y) dengan dibantu program SPSS dalam proses penghitungannya dapat diperoleh hasil sebagai berikut :

\section{Analisis Regresi Berganda}

\section{Coefficients $^{\mathrm{a}}$}

\begin{tabular}{|cl|l|l|l|l|l|}
\hline \multirow{2}{*}{ Model } & \multicolumn{2}{|l|}{$\begin{array}{l}\text { Unstandardized } \\
\text { Coefficients }\end{array}$} & $\begin{array}{l}\text { Standardized } \\
\text { Coefficients }\end{array}$ & & \\
\cline { 2 - 5 } & B & Std. Error & Beta & \multirow{2}{*}{ T } & Sig. \\
\hline 1 & (Constant) & 5.309 & 1.738 & & 3.055 & .004 \\
& HARGA & .427 & .141 & .412 & 3.033 & .004 \\
& KUALITAS & .175 & .141 & .170 & 3.247 & .0021 \\
& & & & & \\
\hline
\end{tabular}

a. Dependent Variable: KEPUASAN PELANGGAN

$$
\mathrm{Y}=0,412 \mathrm{X} 1+0,170 \mathrm{X} 2
$$

Hasil persamaan regresi berganda tersebut di atas memberikan pengertian bahwa :

- $\beta_{1}$ (nilai koefisien regresi $X_{1} 0,412$ ) positif, mempunyai arti bahwa jika Harga Produk $\left(\mathrm{X}_{1}\right)$ semakin kompetitif, maka kepuasan pelanggan akan semakin meningkat.

- $\beta_{2}$ (nilai koefisien regresi $X_{2} 0,170$ ) positif, mempunyai arti bahwa jika kualitas produk $\left(\mathrm{X}_{2}\right)$ yang dijual kepada konsumen baik dan berkualitas tinggi, maka pelanggan yang menggunakan suatu produk tersebut akan semakin puas.

Uji t ini digunakan untuk menganalisis ada atau tidaknya pengaruh antara harga produk $\left(\mathrm{X}_{1}\right)$, kualitas produk $\left(\mathrm{X}_{2}\right)$, terhadap kepuasan pelanggan (Y) secara parsial. 
1. Uji Hipotesis antara Variabel harga produk terhadap kepuasan pelanggan

- Perumusan hipotesis

Ho: $\beta_{1}=0$, artinya tidak ada pengaruh positif yang signifikan antara harga produk $\left(\mathrm{X}_{1}\right)$ terhadap kepuasan pelanggan $(\mathrm{Y})$.

Ha : $\beta_{1}>0$, artinya ada pengaruh yang positif dan signifikan antara Harga Produk $\left(\mathrm{X}_{1}\right)$, terhadap Kepuasan Pelanggan (Y).

Dari hasil perhitungan diperoleh nilai t hitung untuk $\mathrm{X}_{1}$ adalah 30,004 dan dengan menggunakan level significance (taraf signifikan) sebesar $5 \%$ diperoleh $\mathrm{t}$ tabel sebesar 1,667 yang berarti bahwa nilai t hitung lebih besar daripada nilai $\mathrm{t}$ tabel yaitu 3,003 > 1,667. Signifikasi $\mathrm{t}=0,004<0,05$, menandakan bahwa Harga Produk $\left(\mathrm{X}_{1}\right)$ mempunyai pengaruh yang positif dan signifikan terhadap Kepuasan Pelanggan (Y). Dengan demikian dapat disimpulkan bahwa Ho ditolak dan Ha diterima, sehingga hipotesis yang menyatakan dugaan adanya pengaruh yang positif dan signifikan antara kualitas $\operatorname{Produk}\left(\mathrm{X}_{2}\right)$ terhadap Kepuasan Pelanggan(Y) dapat diterima.

2. Uji Hipotesis antara Variabel kualitas produk terhadap Kepuasan Pelanggan

- Perumusan hipotesis

Ho : $\beta_{2}=0$, artinya tidak ada pengaruh positif yang signifikan antara kualitas $\operatorname{produk}\left(\mathrm{X}_{2}\right)$ terhadap Kepuasan Pelanggan (Y).

Ha : $\beta_{2}>0$, artinya ada pengaruh yang positif dan signifikan antara kualitas produk $\left(\mathrm{X}_{2}\right)$, terhadap Kepuasan Pelanggan (Y).

Dari hasil perhitungan diperoleh nilai t hitung untuk kualitas produk $\mathrm{X}_{2}$ adalah 3.247 dan dengan menggunakan level significance (taraf signifikan) 
sebesar $5 \%$ diperoleh $\mathrm{t}$ tabel sebesar 1,667 yang berarti bahwa nilai t hitung lebih besar daripada nilai t tabel yaitu 3.247> 1,667. Signifikasi $t=0,0021<0,05$, menandakan bahwa kualitas produk $\left(\mathrm{X}_{2}\right)$ mempunyai pengaruh yang positif dan signifikan terhadap Kepuasan Pelanggan (Y). Dengan demikian dapat disimpulkan bahwa Ho ditolak dan Ha diterima, sehingga hipotesis yang menyatakan dugaan adanya pengaruh yang positif dan signifikan antara kualitas $\operatorname{produk}\left(\mathrm{X}_{2}\right)$ terhadap Kepuasan Pelanggan (Y) dapat diterima.

\section{Uji F (Uji Model)}

Uji $F$ digunakan untuk uji fit model atau untuk mengetahui baik/buruknya model. Berikut ini adalah hasil uji F.

\section{Uji F}

ANOVA $^{b}$

\begin{tabular}{|ll|l|l|l|l|l|}
\hline \multicolumn{2}{|l|}{ Model } & $\begin{array}{l}\text { Sum } \\
\text { Squares }\end{array}$ & Df & Mean Square & F & Sig. \\
\hline 1 & Regression & 27.746 & 2 & 13.873 & 8.213 & $.001^{\mathrm{a}}$ \\
Residual & 81.077 & 48 & 1.689 & & \\
\multicolumn{1}{|c|}{ Total } & 108.824 & 50 & & & \\
\hline
\end{tabular}

a. Predictors: (Constant), KUALITAS, HARGA

b. Dependent Variable: KEPUASAN

Berdasarkan perhitungan dengan menggunakan program SPSS diperoleh F hitung sebesar 8.213 pada level significance (taraf signifikan) sebesar $5 \%$ diperoleh $\mathrm{F}$ tabel sebesar 3,19 sehingga nilai $\mathrm{F}$ hitung $=8.213>$ dari $\mathrm{F}$ tabel $=3,19$ atau signifikan 0,001 kurang dari 5\%, artinya ada pengaruh antara harga produk dan kualitas produk secara bersama-sama terhadap Kepuasan Pelanggan sehingga model dalam regesi ini adalah baik.

\section{KESIMPULAN DAN SARAN}

\section{Kesimpulan}

Variabel Harga mempunyai pengaruh secara signifikan dan positif terhadap kepuasan pelanggan sehingga hipotesis diterima. Hasil ini membuktikan bahwa pelanggan yang puas terhadap bengkel Alin motor Semarang dengan harga 
produk yang terjangkau dan murah. Dengan demikian semakin harga murah dan terjangkau maka kepuasan pelanggan bengkel Alin motor semarang akan meningkat.

\section{Saran}

Berdasarkan hasil penelitian yang diperoleh, maka saran yang dapat disampaikan oleh penulis kepada Bengkel Alin motor Semarang adalah sebagai berikut :

a. Harga sebuah produk yang ditetapkan oleh bengkel Alin motor semarang masih tergolong mahal jika dibandingkan dengan bengkel disekitarnya, sehingga daya tarik konsumen pun semakin menurun karena tidak diiringi dengan peningkatan pelayanan yang lebih baik. Perlu adanya penyesuaian antara tarif yang dibebankan kepada konsumen dengan penetapan harga yang ditetapkan.

b. Sebaiknya pihak bengkel Alin motor mempertahankan atau meningkatkan kualiatas produk yang dijual kepada pelanggannya atau konsumennya. 


\section{DAFTAR PUSTAKA}

Asri, Marwan. (1991). Marketing. Unit Penerbit dan Percetakan AMP YKPN.

Assauri (1993), terdapat beberapa factor mutu atau kualitas dari suatu produk Yogyakarta.

Augusty Ferdinand.(2006). Metode Penelitian Manajemen : Pedoman Penelitian untuk Penulisan.

Bachriansyah, Rizky Amalia. (2011). "Analisis Pengaruh Kualitas Produk, Daya Tarik Iklan, dan Persepsi Harga Terhadap Minat Beli Konsumen Pada Produk Ponsel Nokia (Studi Kasus Pada Masyarakat Di Kota Semarang)". Fakultas Ekonomi. Universitas Diponegoro, Semarang. Badan Penerbit Universitas Diponegoro.

Barata, AtepAdya, (2004), Dasar-dasar Pelayanan Prima, cetakan kedua,buyers' perception of product quality : an integrative review", Journal of

Dewa, NdaruKusuma. (2009). "analisis pengaruh kualitas produk, daya tarik promosi dan harga terhadap minat beli (studi kasus star one di area Jakarta pusat)", Magister Manajemen Universitas Diponegoro, Semarang.

Doods, Monroe, dangrewal. (1991). effects of price, brand, and store information on buyers product evaluations. Journal of marketing research, vol 28, no.3Edisi 5. Semarang: Badan Penerbit Universitas Diponegoro.

Edy Raharja (2012) Analisis pengaruh kualitas pelayanan harga, dan kepuasan pelanggan. Seto. Jakarta.

Effendi, Guntur. (2010). Transformasi Manajemen Pemasaran. Sagung

Effendi, Guntur. (2010). Transformasi Manajemen Pemasaran. SagungSeto. Jakarta. Erlangga, Jakarta.

Fariza, Diana, (2008), "Analisis Faktor-Faktor yang mempengaruhi Kepuasan Pelanggan Terhadap Kepuasan Pelanggan GSM Indosat di Kota Semarang.

Ghozali, Imam.(2005). Aplikasi Analisis Multivariate dengan Program SPSS. Semarang: Badan Penerbit Universitas Diponegoro

Gito sudarmo, Indriyo, (2008), Manajemen Pemasaran, edisi kedua, cetakan keenam, Penerbit : BPFE - Yogyakarta 
Handoko T. Hani (2000), Dasar-dasar Manajemen Produksi dan Operasi, BPFE, Yogyakarta.

Hasan, Ali, (2008), Marketing, cetakan pertama, Penerbit :Medpress, Yogyakarta

Hermani, Agus. (2003). Membangun kepuasan dan kesetiaan pelanggan.Forum, Vol. 31 No. 1, Hlm. 45-48. Semarang: UNDIP.

Imam Ghozali. (2005). Aplikasi Analisis Multivariate dengan Program SPSS. Semarang: IBM SPSS 19.

Imam Ghozali. (2011). Aplikasi Analisis Multivariate dengan Program

Indah Dwi Kurniasih (2012) pengaruh harga dan kualitas pelayanan terhadap kepuasan pelanggan melalui variable kepuasan.

Kasmir, (2005), Etika Custumer Service, edisi pertama, cetakan pertama, Penerbit :Raja Grafindo Persada, Jakarta keenam, Penerbit : BPFE Yogyakarta

Kotler dan Amstrong, (2001).merancang strategi pemasaran agar dapat menciptakan kepuasan bagi pelanggannya 1997. Prinsip - prinsip pemasaran Jilid I,

Kotler, Philip dan Kevin Lance Keller.(2007). Manajemen Pemasaran. Jilid 1 dan 2 edisi 12.PT. indeks .jakarta.

Kotler, Philip. (1994). Manajemen Pemasaran: Analisis, Perencanaan, Implementasi dan Pengendalian. Jakarta: Erlangga.

Indeks. Jakarta

2005. Manajemen Pemasaran Jilid 1 (11th ed.). PT.

Lerbin R, Aritonang R, (2005), Kepuasan Pelanggan, Pengukuran Dan Penganalisaan Dengan SPSS, edisi pertama, Penerbit : Gramedia

Lopiyoadi, Rambat dan Hamdani A., (2006), Manajemen Pemasaran Jasa, cetakan pertama, edisi kedua, a Penerbit :Salemba Empat, Jakarta

Lupiyoadi, Rambat. (2001). Manajemen Pemasaran Jasa: Teori dan praktik. Jakarta: PT. Salemba Emban Patria.

dimensi,

Madden dan Paul (1997) didalam kualitas produk, terdapat 8 (delapan)

Marketing Research, Vol. 26 (August 1989), p. 351-357 
Emil Salim (2002) Sistemperiodik (physical) yaitu pada setiap akhir periode dilakukan perhitungan secara fisik untuk menentukan jumlah persediaan akhir.

Monroe, Kent B. (1989), "The effect of price, brand name, and store name on Pasien PT. PLN cabang Semarang. Skripsi tidak dipublikasikan. Penerbit :PT. Elex Media Komputindo, Jakarta. Pustaka Utama, Jakarta

PurbadalamKharis (2011) dalam menentukan sampel mengunakan rumus tidak diketahui Pustaka Utama, Jakarta.

SinggihSantoso. (2001). Panduan Lengkap Menguasai Spss 16.Elex Media Komputindo.

\section{Sugiharto.Joko (2009).Analisis Pengaruh Kualitas Pelayanan Terhadap Kepuasan}

Sugiyono, (2004).Metode Penelitian Bisnis. Bandung: CV. Alpha Betha Silverman, George. 2001. The Secrets of Word-of-Mouth Marketing: How to Trigger Expontential Sales through Runaway Word-of-Mouth. US: AmaCom nilai uji $r$ table.

Suharsini Arikunto, (2009) rumus yang digunakan untuk mengetahui

Swasta dan Irawan (2002) motif langganan sering menjadi latar belakang pembelian konsumen.

Tesis, dan Disertasi Ilmu Manajemen. Semarang: Badan Penerbit Universitas Diponegoro.

Tjiptono, Fandy dan Gregorius Chandra, (2005), Service, Quality dan Satisfaction, Penerbit : Andi, Yogyakarta.

Tjiptono, F. (2006).Pemasaran Jasa. Malang: Bayu media Pubhlishing.

Umar, Husein. (2000). Riset Pemasaran dan Perilaku Konsumen, Gramedia

Yamit, Zulian. (2002). Manajemen Kualitas Produk dan Jasa. Jakarta: Ekonissia. 